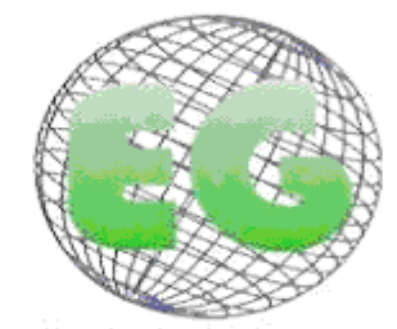

ISSN 1695-6141 $N^{\circ} 23$

\title{
La evaluación en la enseñanza de grado en enfermería en América Latina: una revisión integrativa
}

Avaliação no ensino de graduação em enfermagem na America Latina: uma revisão integrativa

\author{
"Vasconcelos, CM da CB., **Backes, VMS., "**Gue, JM. \\ *Enfermeira e Coordenadora Local de Saúde da Secretaria Municipal de Florianópolis- Santa Catarina. \\ Membro do Grupo de Pesquisa em Educação em Enfermagem e Saúde - EDEN/PEN/UFSC. **Doutora em \\ Enfermagem. Professora Associada do Departamento de Enfermagem e do Programa de Pós-Graduação da \\ Universidade Federal de Santa Catarina - UFSC. Líder do Grupo EDEN/PEN/UFSC. Pesquisadora do CNPq. \\ ***Enfermeira. Doutora em Educação. Docente e pesquisadora do Departamento de Enfermagem e do \\ Programa de Pós-Graduação da Universidade Federal de Santa Catarina - UFSC. Brasil.
}

Palabras clave: Educación; Educación en enfermería; Evaluación educacional; Tecnología educacional; Enfermería

Palavras-chave: Educação; Educação em enfermagem; Avaliação educacional; Tecnologia educacional; Enfermagem.

Keywords: Education; Nursing education; Educational evaluation; Educational technology; Nursing.

\section{RESUMEN}

Artículo de revisión integrativa de la literatura sobre las tendencias o modelos de evaluación en la enseñanza de grado en enfermería que evidencia y discute las diferentes inclinaciones metodológicas adoptadas en Latinoamérica. Como referencial metodológico, se adoptaron las seis etapas de la metodología de Ganong, indicadas para la revisión integrativa de la literatura. Se realizó una revisión bibliográfica en periódicos nacionales, internacionales y una busca activa en las bases de datos SciELO, LILACS, MEDLINE, ABED, BDENF, HOMEOINDEX, PAHO, REPIDISCA, ADOLEC, accedidas vía BVS. El período de la recolección de datos comprendió los meses de mayo a agosto de 2009. Los descriptores seleccionados para la investigación bibliográfica fueron: educación, educación en enfermería, evaluación educacional, tecnología educacional y enfermería. Se observaron 80 artículos completos, publicados entre 2004 y 2008, de entre los cuales se excluyeron 30 artículos, entre producciones duplicadas, cartas, editoriales, resúmenes y producciones no relacionadas con el propósito del estudio, restando 50 artículos para el análisis. La apreciación de los datos evidenció que hay diferentes concepciones pedagógicas adoptadas en la evaluación del proceso de enseñanza y aprendizaje. Hay, por ejemplo, las que se orientan por la concepción de la Escuela Tradicional, con prácticas pedagógicas arraigadas en la concepción 
bancaria de la educación que alienan, enquistan, reproducen posturas ideológicas equivocadas y distorsionadas de esa tendencia. Ya en la concepción de la Escuela Crítica hay un predominio de metodologías de evaluación abiertas, críticas y reflexivas, coherentes con los referenciales teóricos progresistas constructivistas y socio-interaccionistas, orientados por las Directrices Curriculares Nacionales, las cuales facilitan al currículo la búsqueda de la integralidad y de la noción de competencia dialógica, originada en la combinación de atributos (cognitivos, actitudinales y habilidades) que orientan los procesos pedagógicos.

\section{RESUMO}

Artigo de revisão integrativa de literatura sobre as tendências ou modelos de avaliação no ensino de graduação em enfermagem, que evidencia e discute as diferentes inclinações metodológicas adotadas na América Latina. Como referencial metodológico, foram adotadas as seis etapas da metodologia de Ganong, indicadas para a revisão integrativa de literatura. Foi realizada revisão bibliográfica em periódicos nacionais e internacionais e busca ativa nas bases de dados SciELO, LILACS, MEDLINE, ABED, BDENF, Homeolndex, BIREME, WHOLIS, PAHO, REPIDISCA, ADOLEC, acessadas via BVS. O período da coleta de dados foi de maio a agosto de 2009. Os descritores selecionados para a pesquisa bibliográfica foram educação, educação em enfermagem, avaliação educacional, tecnologia educacional e enfermagem. Foram observados 80 artigos completos, publicados entre 2004 e 2008, dos quais se excluiu 30 artigos, entre produções duplicadas, cartas, editoriais, resumos e produções não relacionadas com o escopo do estudo, restando 50 artigos para análise. A apreciação dos dados evidenciou que há diferentes concepções pedagógicas adotadas na avaliação do processo de ensino e aprendizagem. Há, por exemplo, as que se orientam pela concepção da Escola Tradicional, com práticas pedagógicas enraizadas na concepção bancária da educação que alienam, engessam, reproduzem posturas ideológicas equivocadas e distorcidas dessa tendência. Já na concepção da Escola Crítica existe uma predominância de metodologias de avaliação abertas, críticas e reflexivas, coerentes com os referenciais teóricos progressistas construtivistas e sociointeracionistas, orientados pelas Diretrizes Curriculares Nacionais, as quais propiciam ao currículo a busca pela integralidade e pela noção de competência dialógica, originada na combinação de atributos (cognitivos, atitudinais e habilidades) que orientam os processos pedagógicos.

\section{ABSTRACT}

It is an article of integrative literature review on trends or patterns of evaluation in nursing undergraduate courses that highlights and discusses the different methodologies adopted in Latin America. As methodological framework, the six steps of Ganong methodology were adopted, indicated for a integrative literature review. A national, international and active literature review search was conducted in SciELO, LILACS, MEDLINE, ABED, BDENF Homeolndex, PAHO. The descriptors selected for the literature search were education, nursing education, educational evaluation, educational technology and nursing. Eighty articles published from 2004 to 2008 were found, 30 of then were excluded, including duplicate productions, letters, editorials, abstracts and products unrelated to the scope of the study, remaining 50 articles for analysis. Data evaluation indicated different educational concepts adopted in teaching and learning evaluation. There are, for example the ones guided by the concepts of banking education that alienate, imprison and reproduce the distorted and erroneous ideological positions of that trend. In Critical School design there is a predominance of open, critical and reflective evaluation methods consistent with the progressive, constructivist and sociointeractionist theoretical framework guided by the Brazilian National Curriculum Guidelines (PCN), which impels the curriculum to a search for completeness and for the notion of dialogic competence raised from the combination of attributes (cognitive, attitude and skills) that guide the teaching processes. 


\section{INTRODUCCIÓN}

Evaluar es algo que se remonta a la Antigüedad. En Grecia, durante el siglo V a.C., Sócrates aplicaba cuestiones evaluativas como parte de su metodología de enseñanza. En Brasil, la tendencia a considerar la evaluación como sinónimo de pruebas y exámenes es una herencia que data de 1599, introducida por los Jesuitas que trabajaban con la pedagogía tradicional, que se daba por la transmisión de contenidos inmediatos transmitidos a los alumnos sin la participación de estos ${ }^{(1)}$.

Concepciones tradicionales de la educación tratan la evaluación como el acto de medir o cuantificar en notas el saber humano. La evaluación, aunque importante e imprescindible en la planificación educacional, la mayoría de las veces, es vista solamente como un instrumento de selección y de atribución de nota o concepto. Además, es motivo de ansiedad para alumnos y profesores. Por parte de los profesores surgen ambigüedades sobre calidad, lealtad, justicia, integridad, imparcialidad, confiabilidad, privacidad, eficiencia y honestidad de la evaluación. Por parte de los alumnos surge el miedo, la inseguridad, la humillación, la desconfianza, la ira, la indignación, la divergencia. Mientras, es imperativo que profesores y alumnos hagan la distinción entre evaluación y nota o concepto. Pero el cambio de una cultura de evaluación clasificatoria, mantenida durante décadas, no es sencillo y demanda tiempo.

Los currículos de Enfermería tenían una estructura orientada al modelo hospitalocéntrico, mas, en las últimas décadas, fueron transformados y adaptados de acuerdo con la problemática presentada en el contexto de la salud pública brasileña. Ellos expresan los conceptos que dieron origen a los movimentos por cambios en la educación en enfermería, explicitando la necesidad del compromiso con los principios de la Reforma Sanitaria Brasileña y del SUS.

Podemos observar claramente que la evolución de la evaluación en estos movimientos aparece no solamente como fin, sino también como medio, desdoblándose e interactuando con técnicas y metodologías de enseñanza-aprendizaje coherentes con las Directrices Curriculares Nacionales del Curso de Graduación en Enfermería (DCNEnf), las cuales definen que la formación del enfermero tiene por objetivo "dotar al profesional de los conocimientos requeridos para el ejercicio de las siguientes competencias y habilidades generales: atención a la salud, toma de decisiones, comunicación, liderazgo, administración y gerenciamiento y educación permanente"(2).

Las DCNEnf tuvieron su materialidad concretizada a partir de propuestas que surgieron de la movilización de enfermeras(os), a través de la Associação Brasileira de Enfermagem (ABEN), de entidades educativas y de sectores de la sociedad civil interesados en defender los cambios en la formación en las áreas de salud y de educación, las cuales tendieron a la ruptura con las concepciones pedagógicas tradicionales y al avance en propuestas de transformación capaces de alterar las relaciones entre profesoresy alumnos, y de estos con los espacios de enseñanza y aprendizaje, para la construcción del conocimiento y de nuevas prácticas de educación, de enfermería y de salud ${ }^{(3)}$.

Desde este punto de vista, el gran desafío en la formación del enfermero es transponer lo que determina la Lei de Diretrizes e Bases y por las DCNEnf, formando profesionales que superen el dominio teórico-práctico exigido por el mercado de trabajo y se conviertan en agentes innovadores y transformadores de la realidad, insertos y valorizados en el mundo del trabajo.

La enfermería, inmersa en ese escenario de descontento y críticas al modelo tradicional de 
enseñanza, pasó a discutir la reformulación curricular y sus prácticas pedagógicas. Sin embargo, a pesar de las iniciativas de discusión y construcción del proyecto políticopedagógico para enfermería, transcurridas más de dos décadas, todavía hoy se enfrentan políticas socioeconómicas de enseñanza y de salud poco favorables a los procesos de transformación en los servicios de salud y de enfermería. De ahí que sea cada vez más penosa nuestra educación (centralizadora, verbalista, antidialógica, autoritaria y asistencialista), en desacuerdo con nuestra realidad o con aspectos evidentes de ella.

Así, al final del último siglo, el campo de la educación en el área de la salud estuvo marcado por una visión transformadora, basada en teorías críticas, en la concepción constructivista, en la problematización de las prácticas y de los saberes. El objetivo fue oponerse a las posiciones conservadoras, sustentadas por convicciones positivistas, biologicistas, centradas en el profesor y en la transmisión del conocimiento, en detrimento de la calidad del proceso de aprendizaje.

Es sabido que toda actualidad es dinámica y se nutre, entre otros valores, de los que se sitúan en el "ayer" del proceso. De esta forma, al contrario que el periodo anterior, los estudiosos en el tema advierten de que las escuelas tienen que buscar, a través de sus currículos, cambios que atiendan a las necesidades contemporáneas de salud de la población, a la luz de una reflexión crítica sobre su repercusión en la práctica profesional.

Las escuelas de enfermería deben seguir una filosofía de enseñanza que busque formar personas capacitadas para atender las demandas locales y regionales, con compromiso social de cambios. Es en este sentido que las funciones de la evaluación han de ser comprendidas en el contexto de los cambios educacionales y económicos, políticos y sociales más amplios. Este es uno de los aspectos más importantes de nuestra actualidad. Aspecto que el educador atento no puede pasar por alto.

Importante es también considerar que los cursos de graduación en enfermería tienen el reto de romper paradigmas y colocarse en la línea de una formación con pertinencia social y coherencia con los DCNEnf. Es dentro de esa lógica que se espera que las instituciones de enseñanza superior asuman, de forma articulada con el mundo del trabajo, su responsabilidad en la formación del ciudadano para la viabilidad y consolidación del Sistema Único de Salud (SUS), que mira a la universalidad, descentralización y equidad en el acceso a los servicios de salud y al abordaje integral de la persona inserta en la familia y en la sociedad $^{(3)}$.

Así, el proyecto político pedagógico de las instituciones de enseñanza superior habrá de ser pautado en una tendencia pedagógica transformadora, emancipatoria, libertadora y solidaria, con una educación orientada al desarrollo de un profesional consciente de sus responsabilidades y deberes como ciudadano ante su comunidad. Una educación enfocada en el desarrollo de competencias y actitudes críticas, integradas en el conocimiento técnicocientífico de la enfermería.

Esta cuestión nos remite al interior de las escuelas, en donde precisan ser repensados los modelos pedagógicos conservadores, en los que la práctica pedagógica del profesor es la de transmitir conocimientos mientras que los alumnos solo los reciben, sin que haya desarrollo crítico-reflexivo. Por ello, es preciso recordar que buscar lo nuevo no debe significar una batalla contra lo viejo, una negación de la experiencia y de los valores cultivados por una institución y sus educadores. El primer paso es reconocer que no se sabe de todo ${ }^{(4)}$.

Para que tenga lugar el proceso de evaluación pedagógica es necesario que se tenga antes 
la definición de los criterios que dirigen este quehacer, esta práctica, aclarándose para docentes y discentes lo que precisa ser desarrollado exactamente, lo que aún precisa ser trabajado y los puntos que necesitan ser transformados. En consecuencia, de ese tipo de acción saldrá una evaluación de aprendizaje no sólo cuantitativa, sino también cualitativa.

La evaluación no resuelve todos los problemas educativos, pero cuando el profesor tiene la asunción/consciencia de qué debe evaluar, cuándo evaluar, para qué evaluar y de qué forma evaluar, el proceso se hace más visible. Para que eso sea viable en la práctica, es necesario establecer criterios de evaluación precisos, coherentes con el uso de principios, los cuales servirán de fundamento para que se pueda juzgar algo. O sea, principios que tiendan a las "reglas del juego" propiciando la integración entre los sujetos implicados en el proceso de evaluación. Se debe tener en cuenta el "todo" del alumno y una buena parte de esos problemas serán solucionados.

La evaluación en ese sentido precisa constituirse en instrumento que propicie el crecimiento continuo, cumpliendo su función de diagnosticar, reforzar y permitir crecer. Ella debe ser un mecanismo motivador en la que el alumno sea capaz de dominar e incorporar valores, habilidades, competencias, conocimientos, el saber actuar y, principalmente, el saber ser. La cuestión no puede seguir siendo la nota o el concepto, sino el hecho de que el alumno haya aprendido o no.

Estas consideraciónes por sí justifican nuestro interés en desarrollar una revisión integrativa de literatura, en la cual procuramos responder, a lo largo de la investigación, a las siguientes cuestiones: ¿Cómo están configuradas las tendencias o modelos teóricos y metodológicos de evaluación en la enseñanza de graduación de enfermería en América Latina? ¿Qué escuela pedagógica sustenta esos modelos o esas tendencias? ¿Qué instrumentos son adoptados y aplicados en la enseñanza de graduación en enfermería? ¿Cómo están distribuidas las publicaciones científicas en el escenario geográfico de América Latina? ¿Son experiencias consolidadas o todavía incipientes?

Para responder a estas preguntas trazamos como objetivo general: realizar una revisión integrativa de literatura sobre las tendencias o modelos teóricos de evaluación en la enseñanza de graduación de enfermería, evidenciando y discutiendo las diferentes inclinaciones metodológicas adoptadas en América Latina.

\section{EL DISEÑO Y LOS PROCEDIMIENTOS METODOLÓGICOS}

Para alcanzar el objetivo general, optamos por la investigación bibliográfica basada en los presupuestos de la revisión integrativa con enfoque cualitativo, visto que ellos posibilitan resumir las pesquisas ya concluidas y obtener conclusiones a partir de un tema de interés. Por ello, una buena revisión integrativa exige que se observen los mismos patrones de rigor científico, claridad y replicación definidos para los estudios primarios, así como una revisión crítica del contenido investigado.

Aunque los métodos y procedimentos varían en la conducción y operacionalización de la revisión, el análisis de los estudios seleccionados, en relación al diseño de investigación, adoptó las seis etapas de la metodología de Ganong, indicadas para la revisión integrativa de literatura, que son: 1) selección de la cuestión norteadora de la investigación de forma ampliada, propiciando una revisión bibliográfica previa; 2) definición de los criterios de inclusión y exclusión de estudios y selección de la muestra; 3) perfil de los estudios seleccionados en formato de tablas/cuadros, considerando la mejor forma para exponer todas las características en común de las pesquisas primarias; 4) análisis crítico de los 
datos, procurando no comprometer la validez de los estudios revisados; 5) interpretación de los resultados; 6) divulgación de la revisión de forma clara y objetiva, evidenciando el análisis crítico ${ }^{(5)}$.

El levantamiento bibliográfico se realizó a través de internet en el periodo de mayo a agosto de 2009, a través de consultas en periódicos nacionales e internacionales y también con busca activa en base de datos sobre el contenido vigente. Las bases de datos consultadas fueron: SciELO, LILACS, MEDLINE, ABED, BDENF, Homeolndex, BIREME, WHOLIS, PAHO, REPIDISCA, ADOLEC accesadas por medio de la Biblioteca Virtual - BVS), consideradas como las principales del área de salud brasileña.

Para el levantamiento de los artículos utilizamos como descriptores de busca: tendencias/modelos educativos; educación en enfermería; evaluación educativa; tecnología educativa; enfermería. Identificamos con esto 2.038 artículos, que fueron filtrados a partir del perfil y lectura de los resúmenes de los estudios seleccionados y quedaron en 611 artículos, publicados en el periodo de 2000 a 2008. Sin embargo, en el transcurso de la investigación, después de haber adquirido todas las copias y realizado la lectura de los artículos, procurando no comprometer la validez de los estudios revisados ni el rigor metodológico propuesto, consideramos solo 80 artículos, publicados en el período de 2004 a 2008.

El criterio de inclusión definido para la selección de la muestra fue la selección de estudios que trataban la evaluación en la enseñanza superior, dentro de todas las áreas de interés de enfermería, publicados en periódicos nacionales y de América Latina indexados en los bancos de datos LILACS y BDENF. Ello resultó en la lectura y análisis de los datos de 50 artículos, 46 en portugués y 4 en español. Se excluyeron automáticamente 30 publicaciones, al tratarse de producciones (artículos duplicados, cartas, editoriales, resúmenes, tesis, disertaciones) no relacionadas con el alcance del estudio, como evaluación de programas de salud y evaluación de cursos de enfermería, etc.

Como instrumento de colecta de datos se adoptó una planilla de análisis, que permitió ordenar los textos seleccionados por los siguientes temas: escuela pedagógica evidenciada en el estudio; tendencias/modelos e instrumentos de evaluación utilizados en la enseñanza de graduación en enfermería; distribución de las publicaciones científicas en el escenario geográfico de América Latina; y el de que estas se constituyeron en experiencias consolidadas o aún incipientes.

La planilla permitió también disponer de informaciones sobre identificación del artículo, autores y año de publicación; fuente de localización; diseño y características del estudio; coherencia teórico-metodológica; análisis de los datos, resultados y discusión; conclusiones, limitaciones y recomendaciones. El objetivo fue evidenciar y discutir las diferentes inclinaciones metodológicas sobre la evaluación adoptadas en América Latina.

Ante lo expuesto, presentamos una síntesis de los 50 estudios seleccionados para análisis de los datos. Cuadro 1. 
Cuadro 1. Artículos levantados en las bases de datos LILACS e BDENF sobre tendencias o modelos teóricos y metodológicos de evaluación en la enseñanza de graduación de enfermería en América Latina.

\begin{tabular}{|c|c|c|c|c|c|c|}
\hline $\begin{array}{l}\text { TÍTULO DEL } \\
\text { ARTíCULO }\end{array}$ & $\begin{array}{c}\text { ESCUELA } \\
\text { PEDAGÓGICA }\end{array}$ & $\begin{array}{c}\text { TENDENCIA/ } \\
\text { MODELO DE } \\
\text { EVALUACIÓN }\end{array}$ & $\begin{array}{l}\text { PERIÓDICO/ } \\
\text { REVISTA DE } \\
\text { PUBLICACIÓN }\end{array}$ & PAÍS/ESTADO & $\begin{array}{c}\text { BASE } \\
\text { DE } \\
\text { DATOS }\end{array}$ & AÑO \\
\hline $\begin{array}{l}\text { 1- Evaluación } \\
\text { cualitativa de un } \\
\text { programa de } \\
\text { formación de } \\
\text { enfermeras - la } \\
\text { perspectiva de los } \\
\text { profesores y los } \\
\text { estudiantes }\end{array}$ & $\begin{array}{l}\text { Escuela Crítica } \\
\text { (enfoque socio- } \\
\text { constructivista con } \\
\text { un enfoque } \\
\text { etnográfico) }\end{array}$ & $\begin{array}{c}\text { Evaluación de la } \\
\text { Escuela Tradicional y } \\
\text { Sumativa }\end{array}$ & Revista. UDEA & $\begin{array}{l}\text { Colômbia/ } \\
\text { Medellín }\end{array}$ & LILACS & 2008 \\
\hline $\begin{array}{l}\text { 2- Contribuciones } \\
\text { del monitoreo en } \\
\text { el proceso de } \\
\text { enseñanza- } \\
\text { aprendizaje en } \\
\text { enfermería. } \\
\end{array}$ & $\begin{array}{l}\text { Concepción de la } \\
\text { Escuela Tradicional }\end{array}$ & $\begin{array}{l}\text { Evaluación sumativa } \\
\text { sirviéndose de } \\
\text { evidencias }\end{array}$ & $\begin{array}{l}\text { Revista Brasileira } \\
\text { de Enfermagem }\end{array}$ & Brasil/DF-Brasília & LILACS & 2008 \\
\hline $\begin{array}{l}\text { 3- Cambio } \\
\text { curricular: } \\
\text { desafio de un } \\
\text { curso de } \\
\text { graduación en } \\
\text { enfermería } \\
\end{array}$ & $\begin{array}{l}\text { Concepción de la } \\
\text { Escuela Tradicional }\end{array}$ & $\begin{array}{l}\text { Evaluación } \\
\text { Tradicional } \\
\text { (Sumativa) }\end{array}$ & $\begin{array}{l}\text { Revista Brasileira } \\
\text { de Enfermagem }\end{array}$ & Brasil/DF-Brasília & LILACS & 2008 \\
\hline $\begin{array}{l}\text { 4- El portafolio } \\
\text { reflexivo: } \\
\text { pareceres de los } \\
\text { estudiantes de } \\
\text { enfermería }\end{array}$ & $\begin{array}{l}\text { Concepción de la } \\
\text { Escuela Crítica } \\
\text { (metodologías } \\
\text { activas de aprendi- } \\
\text { zaje) }\end{array}$ & $\begin{array}{c}\text { Evaluación } \\
\text { Formativa con el uso } \\
\text { del portafolio como } \\
\text { instrumento de } \\
\text { evaluación }\end{array}$ & $\begin{array}{c}\text { Revista } \\
\text { Iberoamericana de } \\
\text { Educación }\end{array}$ & $\begin{array}{l}\text { Organización de } \\
\text { Estados } \\
\text { Iberoamerica-nos } \\
\text { para la Educación, } \\
\text { la Ciencia y la } \\
\text { Cultura (OEI) } \\
\end{array}$ & LILACS & 2008 \\
\hline $\begin{array}{l}\text { 5- Pensando en la } \\
\text { formación de } \\
\text { futuros } \\
\text { profesionales de } \\
\text { enfermería en } \\
\text { América Latina }\end{array}$ & $\begin{array}{l}\text { Concepción de la } \\
\text { Escuela Crítica, } \\
\text { desde una } \\
\text { perspectiva } \\
\text { dialógica, solidaria y } \\
\text { humanizada }\end{array}$ & $\begin{array}{c}\text { Evaluacióno } \\
\text { formativa (modelo } \\
\text { por competencias) }\end{array}$ & $\begin{array}{l}\text { Revista Investi- } \\
\text { gación Educaçión. } \\
\text { Enfermaría. }\end{array}$ & Colômbia/Medellín & LILACS & 2008 \\
\hline $\begin{array}{l}\text { 6- És posible } \\
\text { pensar de otro } \\
\text { modo la } \\
\text { educación en } \\
\text { enfermería. }\end{array}$ & $\begin{array}{l}\text { Concepción de la } \\
\text { Escuela Crítica }\end{array}$ & $\begin{array}{l}\text { Indica la evaluación } \\
\text { formativaen el } \\
\text { modelo por } \\
\text { competencias }\end{array}$ & $\begin{array}{l}\text { Revista da Escola } \\
\text { de Enfermagem } \\
\text { Anna Nery }\end{array}$ & $\begin{array}{l}\text { Brasil/Rio de } \\
\text { Janeiro }\end{array}$ & LILACS & 2008 \\
\hline $\begin{array}{l}\text { 7- La educación } \\
\text { en enfermería a la } \\
\text { luz del paradigma } \\
\text { de la complejidad }\end{array}$ & $\begin{array}{l}\text { Pedagogía de la } \\
\text { Escuela Crítica } \\
\text { (Teoría de la } \\
\text { Complejidad, de } \\
\text { Edgar Morin) } \\
\end{array}$ & $\begin{array}{c}\text { Para una Evaluación } \\
\text { Formativa (procesal/ } \\
\text { emancipatoória) }\end{array}$ & $\begin{array}{c}\text { Revista Escola } \\
\text { Enfermagem/USP }\end{array}$ & Brasil/São Paulo & LILACS & 2007 \\
\hline $\begin{array}{l}\text { 8- Finalidades y } \\
\text { función de la } \\
\text { evaluación en la } \\
\text { formación de } \\
\text { enfermeros }\end{array}$ & $\begin{array}{l}\text { Concepción de la } \\
\text { Escuela Crítica }\end{array}$ & $\begin{array}{l}\text { Evaluación por } \\
\text { competencias }\end{array}$ & $\begin{array}{l}\text { Revista Brasileira } \\
\text { de Enfermagem }\end{array}$ & Brasil/São Paulo & LILACS & 2007 \\
\hline $\begin{array}{l}\text { 9- Proceso } \\
\text { evaluativo en } \\
\text { etapas } \\
\text { supervisadas: una } \\
\text { contribución para } \\
\text { el estudio }\end{array}$ & $\begin{array}{l}\text { Concepción de la } \\
\text { Escuela Tradicional }\end{array}$ & $\begin{array}{l}\text { Evaluación } \\
\text { Tradicional } \\
\text { (sumativa) }\end{array}$ & $\begin{array}{l}\text { Revista Cogitare } \\
\text { Enfermagem }\end{array}$ & Brasil/São Paulo & LILACS & 2007 \\
\hline
\end{tabular}




\begin{tabular}{|c|c|c|c|c|c|c|}
\hline $\begin{array}{l}\text { 10- Evaluación de } \\
\text { la enseñanza de la } \\
\text { disciplina } \\
\text { Enfermería } \\
\text { Geronto-eriátrica } \\
\text { del curso de } \\
\text { graduación en } \\
\text { enfefrmería de la } \\
\text { FURG }\end{array}$ & $\begin{array}{l}\text { Concepción de la } \\
\text { Escuela Tradicional } \\
\text { (Estudio de caso } \\
\text { histórico- } \\
\text { organizacional) }\end{array}$ & $\begin{array}{l}\text { Evaluación } \\
\text { Tradicional } \\
\text { (sumativa) }\end{array}$ & $\begin{array}{l}\text { Revista Cogitare } \\
\text { Enfermagem }\end{array}$ & Brasil/São Paulo & LILACS & 2007 \\
\hline $\begin{array}{l}11 \text { - La tutoría } \\
\text { académica en el } \\
\text { contexto histórico } \\
\text { de la educación }\end{array}$ & $\begin{array}{l}\text { Escuela Crítica } \\
\text { (Pedagogía del } \\
\text { cuidado) }\end{array}$ & $\begin{array}{l}\text { Evaluación por } \\
\text { competencias }\end{array}$ & $\begin{array}{l}\text { Revista Brasileira } \\
\text { de Enfermagem }\end{array}$ & Brasil/DF-Brasília & LILACS & 2007 \\
\hline $\begin{array}{l}\text { 12- Desarrollo y } \\
\text { utilización de } \\
\text { objetos } \\
\text { educacionales } \\
\text { digitales en } \\
\text { laenseñanza de } \\
\text { enfermería }\end{array}$ & $\begin{array}{l}\text { Concepción de la } \\
\text { Escuela Crítica } \\
\text { (los referenciales } \\
\text { pedagógicos del } \\
\text { aprendizaje están } \\
\text { basados en } \\
\text { problemas y en el } \\
\text { constructivismo } \\
\text { interacionista.) }\end{array}$ & $\begin{array}{l}\text { No indica el tipo de } \\
\text { evaluación utilizada, } \\
\text { pues el estudio en la } \\
\text { época no estaba } \\
\text { concluido. Por ello se } \\
\text { percibe que los } \\
\text { alumnos al utilizar } \\
\text { estos recursos son } \\
\text { más autónomos } \\
\text { durante el proceso de } \\
\text { enseñanza y } \\
\text { aprendizaje. }\end{array}$ & $\begin{array}{c}\text { Revista } \\
\text { Latino-Americana } \\
\text { de Enfermagem }\end{array}$ & Brasil/São Paulo & LILACS & 2007 \\
\hline $\begin{array}{l}13 \text { - El papel de } \\
\text { los tutores en la } \\
\text { auto-dirección del } \\
\text { aprendizaje de los } \\
\text { estudiantes de } \\
\text { enfermería }\end{array}$ & $\begin{array}{l}\text { Concepción de la } \\
\text { Escuela Crítica } \\
\text { (método de } \\
\text { Aprendizaje Basado } \\
\text { en Problemas - } \\
\text { ABP) }\end{array}$ & $\begin{array}{l}\text { Evaluación por } \\
\text { competencias }\end{array}$ & $\begin{array}{c}\text { Revista de } \\
\text { Investigación y } \\
\text { Educación en } \\
\text { Enfermería da } \\
\text { Universidad de } \\
\text { Antioquia - } \\
\text { Facultad/Medellín. }\end{array}$ & Colômbia/Medellín & LILACS & 2007 \\
\hline $\begin{array}{l}\text { 14- La formación } \\
\text { del enfermero: } \\
\text { contradiciones y } \\
\text { desafíos en la } \\
\text { prcática } \\
\text { pedagógica }\end{array}$ & $\begin{array}{l}\text { Concepción de la } \\
\text { Escuela Tradicional } \\
\text { - biomédico- } \\
\text { tecnicista }\end{array}$ & $\begin{array}{l}\text { Evaluación } \\
\text { Tradicional } \\
\text { (sumativa) }\end{array}$ & $\begin{array}{c}\text { Revista } \\
\text { Latino-Americana } \\
\text { de Enfermagem } \\
\text { (On-line) }\end{array}$ & Brasil/São Paulo & LILACS & 2007 \\
\hline $\begin{array}{l}\text { 15- Pedagogía } \\
\text { problematizadora: } \\
\text { la relación } \\
\text { interpersonal de } \\
\text { los internos de } \\
\text { enfermería en el } \\
\text { contexto } \\
\text { hospitalario }\end{array}$ & $\begin{array}{l}\text { Concepción de la } \\
\text { Teoría Crítica de la } \\
\text { educación }\end{array}$ & $\begin{array}{c}\text { Evalaución } \\
\text { Formativa }\end{array}$ & $\begin{array}{c}\text { Revista } \\
\text { Enfermagem } \\
\text { UERJ }\end{array}$ & $\begin{array}{l}\text { Brasil/Rio de } \\
\text { Janeiro }\end{array}$ & LILACS & 2007 \\
\hline $\begin{array}{l}\text { 16- Directrices } \\
\text { Curriculares de la } \\
\text { Graduación de } \\
\text { Enfermería: } \\
\text { pensando } \\
\text { contextos, } \\
\text { cambios y } \\
\text { perspectivas }\end{array}$ & $\begin{array}{l}\text { Concepción de la } \\
\text { Escuela Crítica }\end{array}$ & $\begin{array}{c}\text { Evalaución por } \\
\text { competencias y } \\
\text { habilidades generales. }\end{array}$ & $\begin{array}{l}\text { Revista Brasileira } \\
\text { de Enfermagem }\end{array}$ & Brasil/DF-Brasília & LILACS & 2007 \\
\hline $\begin{array}{l}\text { 17- Cuidando del } \\
\text { Educando:la } \\
\text { socio-poética } \\
\text { sensibilizando la } \\
\text { Formación del } \\
\text { cuidador }\end{array}$ & $\begin{array}{l}\text { Concepción de la } \\
\text { Escuela Crítica } \\
\text { (Sociopoética) }\end{array}$ & $\begin{array}{c}\text { Evaluación } \\
\text { Formativa }\end{array}$ & $\begin{array}{l}\text { Revista } \\
\text { Enfermagem } \\
\text { UERJ }\end{array}$ & $\begin{array}{l}\text { Brasil/Rio de } \\
\text { Janeiro }\end{array}$ & LILACS & 2007 \\
\hline $\begin{array}{l}\text { 18- La práctica de } \\
\text { enseñar y }\end{array}$ & $\begin{array}{l}\text { Concepción de la } \\
\text { Escuela Crítica }\end{array}$ & $\begin{array}{c}\text { Evaluación por } \\
\text { competencias }\end{array}$ & $\begin{array}{l}\text { Portal de Revistas } \\
\text { Científicas em }\end{array}$ & Brasil/RJ-Niterói & LILACS & 2007 \\
\hline
\end{tabular}




\begin{tabular}{|c|c|c|c|c|c|c|}
\hline $\begin{array}{l}\text { aprender } \\
\text { administración en } \\
\text { enfermería } \\
\text { basada en la } \\
\text { metodología } \\
\text { freireana. }\end{array}$ & $\begin{array}{l}\text { (Metodología } \\
\text { Problematizadora - } \\
\text { Freire) }\end{array}$ & & $\begin{array}{l}\text { Ciências da Saúde } \\
\text { (on-line - BVS) }\end{array}$ & & & \\
\hline $\begin{array}{l}\text { 19- La } \\
\text { perspectiva } \\
\text { estética en el } \\
\text { cuidar/educar } \\
\text { junto a las } \\
\text { personas: } \\
\text { Apropiación y } \\
\text { contribución de la } \\
\text { sócio-poética }\end{array}$ & $\begin{array}{l}\text { Concepción de la } \\
\text { Escuela Crítica. }\end{array}$ & $\begin{array}{c}\text { Evaluación del } \\
\text { proceso educativo - } \\
\text { debe tener el sentido } \\
\text { de resignificación en } \\
\text { la diversidad }\end{array}$ & $\begin{array}{l}\text { Revista Texto \& } \\
\text { Contexto Enfer- } \\
\text { magem }\end{array}$ & $\begin{array}{c}\text { Brasil/SC } \\
\text { Florianópolis }\end{array}$ & LILACS & 2006 \\
\hline $\begin{array}{l}\text { 20- La educación } \\
\text { de enfermería: } \\
\text { buscando la } \\
\text { formación crítico- } \\
\text { reflexiva y las } \\
\text { competencias } \\
\text { profesionales }\end{array}$ & $\begin{array}{l}\text { Concepción de la } \\
\text { Escuela Crítico- } \\
\text { Reflexiva. }\end{array}$ & $\begin{array}{c}\text { Evalaución } \\
\text { Formativa y por } \\
\text { competencias }\end{array}$ & $\begin{array}{l}\text { Revista Latino- } \\
\text { Americana de } \\
\text { Enfermagem (On- } \\
\text { line) }\end{array}$ & Brasil/São Paulo & LILACS & 2006 \\
\hline $\begin{array}{l}\text { 21- La enseñanza } \\
\text { de enfermería y } \\
\text { las directrices } \\
\text { curriculares } \\
\text { nacionales: utopía } \\
\text { x realidad }\end{array}$ & $\begin{array}{l}\text { Concepción de la } \\
\text { Escuela Crítica }\end{array}$ & $\begin{array}{c}\text { Evaluación } \\
\text { Formativa (modelo } \\
\text { por competencias) }\end{array}$ & $\begin{array}{c}\text { Revista Escola } \\
\text { Enfermagem/USP }\end{array}$ & Brasil/São Paulo & LILACS & 2006 \\
\hline $\begin{array}{l}\text { 22- Directrices } \\
\text { curriculares y } \\
\text { estrategias para la } \\
\text { implantacióno de } \\
\text { una nueva } \\
\text { propuesta } \\
\text { pedagógica }\end{array}$ & $\begin{array}{l}\text { Concepción de la } \\
\text { Escuela Crítica } \\
\text { (Metodologías } \\
\text { Activas) }\end{array}$ & $\begin{array}{l}\text { Evaluación por } \\
\text { competencias }\end{array}$ & $\begin{array}{c}\text { Revista Escola } \\
\text { Enfermagem/USP }\end{array}$ & Brasil/São Paulo & LILACS & 2006 \\
\hline $\begin{array}{l}\text { 23- Pedagogía de } \\
\text { las competencias } \\
\text { - un referencial } \\
\text { para la transición } \\
\text { paradigmática en } \\
\text { la enseñanza de } \\
\text { Enfermería - una } \\
\text { revisión de la } \\
\text { literatura }\end{array}$ & $\begin{array}{l}\text { Concepción de la } \\
\text { Escuela Crítica } \\
\text { (Referencial } \\
\text { Teórico: } \\
\text { Constructivismo) }\end{array}$ & $\begin{array}{l}\text { Evaluación por } \\
\text { competencias }\end{array}$ & $\begin{array}{l}\text { Revista Acta } \\
\text { Paulista de } \\
\text { Enfermagem }\end{array}$ & Brasil/São Paulo & LILACS & 2006 \\
\hline $\begin{array}{l}\text { 24- La enseñanza } \\
\text { de enfermería } \\
\text { como espacio } \\
\text { para el desarrollo } \\
\text { de tecnologias de } \\
\text { educación en } \\
\text { salud }\end{array}$ & $\begin{array}{l}\text { Concepción de la } \\
\text { Escuela Crítica } \\
\text { (Metodología } \\
\text { Problematizadora) }\end{array}$ & $\begin{array}{l}\text { Evaluación } \\
\text { Formativa }\end{array}$ & $\begin{array}{l}\text { Revista Gaúcha de } \\
\text { Enfermagem }\end{array}$ & $\begin{array}{c}\text { Brasil/ RS } \\
\text { Porto Alegre }\end{array}$ & LILACS & 2006 \\
\hline $\begin{array}{l}\text { 25- El modelo de } \\
\text { educación de } \\
\text { laboratorio en la } \\
\text { formación del } \\
\text { enfermero: } \\
\text { evaluación del } \\
\text { graduando de } \\
\text { enfermería }\end{array}$ & $\begin{array}{l}\text { Concepción de la } \\
\text { Escuela Crítica }\end{array}$ & $\begin{array}{l}\text { Evalaución por } \\
\text { competencia }\end{array}$ & $\begin{array}{c}\text { Revista de } \\
\text { Enfermagem } \\
\text { UERJ }\end{array}$ & $\begin{array}{l}\text { Brasil/Rio de } \\
\text { Janeiro }\end{array}$ & LILACS & 2006 \\
\hline $\begin{array}{l}\text { 26-Desarrollo } \\
\text { curricular del } \\
\text { curso de }\end{array}$ & $\begin{array}{l}\text { Concepción de la } \\
\text { Escuela Crítica }\end{array}$ & $\begin{array}{l}\text { Evalaución utilizada: } \\
\text { concepción dialógica } \\
\text { de competencias }\end{array}$ & $\begin{array}{c}\text { REME - Revista } \\
\text { Mineira de } \\
\text { Enfermagem }\end{array}$ & $\begin{array}{c}\text { Brasil/Minas } \\
\text { Gerais }\end{array}$ & LILACS & 2006 \\
\hline
\end{tabular}




\begin{tabular}{|c|c|c|c|c|c|c|}
\hline $\begin{array}{l}\text { enfermería de la } \\
\text { FANEMA: } \\
\text { contexto actual }\end{array}$ & & & & & & \\
\hline $\begin{array}{l}\text { 27- La aplicación } \\
\text { del modelo de } \\
\text { educación de } \\
\text { laboratorio en el } \\
\text { proceso de } \\
\text { formación del } \\
\text { enfermero }\end{array}$ & $\begin{array}{l}\text { Concepción de la } \\
\text { Escuela Crítica }\end{array}$ & $\begin{array}{l}\text { Evaluación por } \\
\text { Competencia }\end{array}$ & $\begin{array}{c}\text { Revista de } \\
\text { Enfermagem } \\
\text { UERJ }\end{array}$ & $\begin{array}{l}\text { Brasil/Rio de } \\
\text { Janeiro }\end{array}$ & LILACS & 2005 \\
\hline $\begin{array}{l}\text { 28- El proceso de } \\
\text { enseñanza y } \\
\text { aprendizaje en } \\
\text { situación de } \\
\text { estágio en } \\
\text { enfermería: } \\
\text { discusiones } \\
\text { teóricas acerca } \\
\text { del proceso } \\
\text { evauiativo }\end{array}$ & $\begin{array}{l}\text { Concepción de la } \\
\text { Escuela Crítica } \\
\text { (Teoria histórico- } \\
\text { social de Vygotsky) }\end{array}$ & $\begin{array}{c}\text { Evaluación } \\
\text { Formativa (vista } \\
\text { como proceso) }\end{array}$ & $\begin{array}{l}\text { Revista Ciência, } \\
\text { Cuidado e Saúde }\end{array}$ & Brasil/PR-Maringá & LILACS & 2005 \\
\hline $\begin{array}{l}29- \\
\text { Reflexionando } \\
\text { sobre la } \\
\text { educación y el } \\
\text { trabajo de } \\
\text { enfermería a la } \\
\text { luz de las ideas de } \\
\text { Paulo Freire: la } \\
\text { posibilidad de un } \\
\text { nuevo mirar para } \\
\text { la educación. }\end{array}$ & $\begin{array}{l}\text { Concepción de la } \\
\text { Escuela Crítica, } \\
\text { pautada en Paulo } \\
\text { Freire y en el } \\
\text { Constructivismo }\end{array}$ & $\begin{array}{c}\text { Evaluación dentro de } \\
\text { la perspectiva crítica } \\
\text { dialógica }\end{array}$ & $\begin{array}{l}\text { Revista Ciência, } \\
\text { Cuidado e Saúde }\end{array}$ & Brasil/PR-Maringá & LILACS & 2005 \\
\hline $\begin{array}{l}\text { 30- Cómo } \\
\text { acompañar la } \\
\text { progresión de la } \\
\text { competencia } \\
\text { comunicativa en } \\
\text { el alumno de } \\
\text { Enfermería }\end{array}$ & $\begin{array}{l}\text { Concepción de la } \\
\text { Escuela Crítica } \\
\text { aliada con la Escuela } \\
\text { Tradicional }\end{array}$ & $\begin{array}{c}\text { Evalaución } \\
\text { Formativa y sumativa }\end{array}$ & $\begin{array}{l}\text { Revista Ciência, } \\
\text { Cuidado e Saúde }\end{array}$ & Brasil/PR-Maringá & LILACS & 2005 \\
\hline $\begin{array}{l}\text { 31- Psicodrama } \\
\text { pedagógico: } \\
\text { estrategia para la } \\
\text { enseñanza en } \\
\text { enfermería }\end{array}$ & $\begin{array}{l}\text { Escuela Crítica } \\
\text { (Metodologías } \\
\text { Activas) }\end{array}$ & $\begin{array}{c}\text { Evaluación } \\
\text { Formativa -modelo } \\
\text { por competencias }\end{array}$ & $\begin{array}{c}\text { Revista Ciencia y } \\
\text { Enfermería }\end{array}$ & Chile/Concepción & LILACS & 2004 \\
\hline $\begin{array}{l}\text { 32- Contribución } \\
\text { a la renovación } \\
\text { de los enfoques } \\
\text { pedagógicos en el } \\
\text { proceso de } \\
\text { formación de } \\
\text { enfermeros. }\end{array}$ & $\begin{array}{l}\text { Concepción de la } \\
\text { Escuela Crítica }\end{array}$ & $\begin{array}{c}\text { Evaluación } \\
\text { Formativa - modelo } \\
\text { por competencias }\end{array}$ & $\begin{array}{c}\text { Revista Cogitare } \\
\text { Enfermagem }\end{array}$ & Brasil/Paraná & LILACS & 2004 \\
\hline $\begin{array}{l}\text { 33- Construcción } \\
\text { de una práxis } \\
\text { educativa en } \\
\text { informática en } \\
\text { salud para } \\
\text { enseñanza de } \\
\text { graduación }\end{array}$ & $\begin{array}{l}\text { Concepción de la } \\
\text { Escuela Crítica }\end{array}$ & $\begin{array}{l}\text { Evaluación } \\
\text { Formativa } \\
\text { (diagnóstica) }\end{array}$ & $\begin{array}{l}\text { Revista Ciência da } \\
\text { Saúde Coletiva }\end{array}$ & Brasil/Bahia & BDENF & 2008 \\
\hline $\begin{array}{l}\text { 34- Instrumento } \\
\text { de evaluación del } \\
\text { alumno basado en }\end{array}$ & $\begin{array}{l}\text { Concepción de la } \\
\text { Escuela Crítica }\end{array}$ & $\begin{array}{c}\text { Evaluación } \\
\text { Formativa (modelo } \\
\text { por competencia) }\end{array}$ & $\begin{array}{l}\text { Revista Acta } \\
\text { Paulista. }\end{array}$ & Brasil/São Paulo & BDENF & 2008 \\
\hline
\end{tabular}




\begin{tabular}{|c|c|c|c|c|c|c|}
\hline $\begin{array}{l}\text { las competencias } \\
\text { gerencialeis del } \\
\text { enfermero. }\end{array}$ & & & & & & \\
\hline $\begin{array}{l}\text { 35- Las } \\
\text { potencialidades y } \\
\text { fragilidades del } \\
\text { portafolio } \\
\text { reflexivo en la } \\
\text { visión de los } \\
\text { estudiantes de } \\
\text { enfermería }\end{array}$ & $\begin{array}{l}\text { Concepción de la } \\
\text { Escuela Crítica }\end{array}$ & $\begin{array}{l}\text { Evaluación } \\
\text { Formativa (Utilizan } \\
\text { el portafolio como } \\
\text { herramienta del } \\
\text { proceso de } \\
\text { enseñanza- } \\
\text { aprendizaje.) }\end{array}$ & $\begin{array}{c}\text { Revista de } \\
\text { Enfermagem } \\
\text { UERJ }\end{array}$ & $\begin{array}{l}\text { Brasil/Rio de } \\
\text { Janeiro }\end{array}$ & BDENF & 2008 \\
\hline $\begin{array}{l}\text { 36- Aplicación de } \\
\text { manual educativo } \\
\text { sobre la piel del } \\
\text { recién-nacido con } \\
\text { estudiantes de } \\
\text { Enfermería }\end{array}$ & $\begin{array}{l}\text { Concepción de la } \\
\text { Escuela Tradicional } \\
\text { (mas entienden que } \\
\text { hoy la enseñanza } \\
\text { debe guiarse a la luz } \\
\text { de las tendencias } \\
\text { educacionales } \\
\text { progresistas). }\end{array}$ & $\begin{array}{l}\text { Los alumnos } \\
\text { reconocen que el uso } \\
\text { de nuevas } \\
\text { tecnologías/ } \\
\text { estrategias de } \\
\text { enseñanza favorece } \\
\text { un aprendizaje más } \\
\text { global y } \\
\text { emancipatorio }\end{array}$ & $\begin{array}{l}\text { Revista Eletrônica } \\
\text { de Enfermagem }\end{array}$ & $\begin{array}{c}\text { Brasil/CE- } \\
\text { Fortaleza }\end{array}$ & BDENF & 2007 \\
\hline $\begin{array}{l}\text { 37- Enseñanza de } \\
\text { didáctica en } \\
\text { enfermería } \\
\text { mediada por el } \\
\text { computador: } \\
\text { evaluación } \\
\text { discente }\end{array}$ & $\begin{array}{l}\text { Concepción de la } \\
\text { Escuela Crítica }\end{array}$ & $\begin{array}{c}\text { Evaluación } \\
\text { Formativa }\end{array}$ & $\begin{array}{l}\text { Revista da Escola } \\
\text { de Enfermagem da } \\
\text { USP }\end{array}$ & Brasil/São Paulo & BDENF & 2007 \\
\hline $\begin{array}{l}\text { 38- Cómo } \\
\text { acompañar la } \\
\text { progresión de la } \\
\text { competencia } \\
\text { comunicativa en } \\
\text { el alumno de } \\
\text { Enfermería }\end{array}$ & $\begin{array}{l}\text { Concepción de la } \\
\text { Escuela Crítica } \\
\text { Construcivista }\end{array}$ & $\begin{array}{c}\text { Evaluación } \\
\text { Formativa (modelo } \\
\text { por competencia) }\end{array}$ & $\begin{array}{l}\text { Revista da Escola } \\
\text { de Enfermagem da } \\
\text { USP }\end{array}$ & Brasil/São Paulo & BDENF & 2006 \\
\hline $\begin{array}{l}\text { 39- La } \\
\text { construcción de } \\
\text { un software } \\
\text { educativo sobre } \\
\text { escucha de los } \\
\text { sonidos } \\
\text { respiratorios }\end{array}$ & $\begin{array}{l}\text { Concepción de la } \\
\text { Escuela Crítica } \\
\text { Socioconstrutivista }\end{array}$ & $\begin{array}{l}\text { Evaluación } \\
\text { Formativa }\end{array}$ & $\begin{array}{l}\text { Revista da Escola } \\
\text { de Enfermagem da } \\
\text { USP }\end{array}$ & Brasil/São Paulo & BDENF & 2006 \\
\hline $\begin{array}{l}\text { 40- Reflexiones } \\
\text { sobre la } \\
\text { enseñanza de la } \\
\text { enfermería y los } \\
\text { primeros } \\
\text { contactos del } \\
\text { alumno con la } \\
\text { profesion }\end{array}$ & $\begin{array}{l}\text { Concepción de la } \\
\text { Escuela Crítica }\end{array}$ & $\begin{array}{l}\text { Evaluación por } \\
\text { competencias }\end{array}$ & $\begin{array}{c}\text { Revista } \\
\text { Latino-Americana } \\
\text { de Enfermagem }\end{array}$ & Brasil/São Paulo & BDENF & 2006 \\
\hline $\begin{array}{l}\text { 41- La } \\
\text { dramatización } \\
\text { como recurso en } \\
\text { el proceso } \\
\text { enseñanza y } \\
\text { aprendizaje en la } \\
\text { disciplina de } \\
\text { historia de la } \\
\text { enfermería }\end{array}$ & $\begin{array}{l}\text { Concepción de la } \\
\text { Escuela Tradicional }\end{array}$ & Evaluación Sumativa & $\begin{array}{l}\text { Revista Cogitare } \\
\text { Enfermagem }\end{array}$ & Brasil/São Paulo & BDENF & 2006 \\
\hline $\begin{array}{l}\text { 42- Aprendiendo } \\
\text { a cuidar: la } \\
\text { sensibilidad como }\end{array}$ & $\begin{array}{l}\text { Concepción de la } \\
\text { Escuela Crítica }\end{array}$ & $\begin{array}{l}\text { Evaluación por } \\
\text { Competencias }\end{array}$ & $\begin{array}{c}\text { Revista } \\
\text { Texto \& Contexto } \\
\text { Enfermagem }\end{array}$ & $\begin{array}{c}\text { Brasil// } \\
\text { SC-Florianópolis }\end{array}$ & BDENF & 2006 \\
\hline
\end{tabular}




\begin{tabular}{|c|c|c|c|c|c|c|}
\hline $\begin{array}{l}\text { elemento } \\
\text { plasmático para la } \\
\text { formación del } \\
\text { profesional } \\
\text { crítico-creativo } \\
\text { en enfermería. }\end{array}$ & & & & & & \\
\hline $\begin{array}{l}\text { 43- La teoría de } \\
\text { la actividad como } \\
\text { referencial } \\
\text { conceptual para la } \\
\text { enfermería }\end{array}$ & $\begin{array}{l}\text { Concepción de la } \\
\text { Escuela Crítica } \\
\text { pautada en el } \\
\text { socioconstructivismo }\end{array}$ & $\begin{array}{l}\text { Evaluación } \\
\text { Formativa }\end{array}$ & $\begin{array}{l}\text { Revista de Gaúcha } \\
\text { Enfermagem }\end{array}$ & $\begin{array}{c}\text { Brasil// } \\
\text { RS-Porto Alegre }\end{array}$ & BDENF & 2006 \\
\hline $\begin{array}{l}\text { 44- Referencias } \\
\text { para la enseñanza } \\
\text { de competencias } \\
\text { en enfermería }\end{array}$ & $\begin{array}{l}\text { Concepción de la } \\
\text { Escuela Crítica }\end{array}$ & $\begin{array}{c}\text { Evaluación } \\
\text { Formativa (recurso } \\
\text { para la enseñanza por } \\
\text { competencias) }\end{array}$ & $\begin{array}{c}\text { Revista Brasileira } \\
\text { de Enfermagem }\end{array}$ & Brasil/DF-Brasília & BDENF & 2005 \\
\hline $\begin{array}{l}\text { 45- La inserción } \\
\text { de la música en la } \\
\text { enseñanza } \\
\text { superior de } \\
\text { enfermería: un } \\
\text { relato de } \\
\text { experiencia }\end{array}$ & $\begin{array}{l}\text { Concepción de la } \\
\text { Escuela Tradicional, } \\
\text { con un enfoque de } \\
\text { transición para la } \\
\text { Escuela Crítica }\end{array}$ & $\begin{array}{c}\text { Evaluación Sumativa } \\
\text { y Formativa }\end{array}$ & $\begin{array}{l}\text { Revista Ciência, } \\
\text { Cuidado e Saúde }\end{array}$ & Brasil/PR-Maringá & BDENF & 2005 \\
\hline $\begin{array}{l}\text { 46- Enfoque por } \\
\text { competencias en } \\
\text { el proceso } \\
\text { enseñanza- } \\
\text { aprendizaje }\end{array}$ & $\begin{array}{l}\text { Concepción de la } \\
\text { Escuela Crítica }\end{array}$ & $\begin{array}{l}\text { Evaluación por } \\
\text { Competencias }\end{array}$ & $\begin{array}{l}\text { Revista Brasileira } \\
\text { de Enfermagem }\end{array}$ & Brasil/DF-Brasília & BDENF & 2005 \\
\hline $\begin{array}{l}\text { 47- Transición } \\
\text { para el ejercício } \\
\text { profesional en } \\
\text { enfermería: una } \\
\text { experiencia en } \\
\text { grupo operativo }\end{array}$ & $\begin{array}{l}\text { Referencial de la } \\
\text { Escuela Tradicional }\end{array}$ & $\begin{array}{l}\text { No apunta, por eso el } \\
\text { estudio señala al } \\
\text { modelo de } \\
\text { metodología utilizado } \\
\text { en la Escuela Crítica } \\
\text { (transción) }\end{array}$ & $\begin{array}{l}\text { Revista da Escola } \\
\text { de Enfermagem } \\
\text { Anna Nery }\end{array}$ & $\begin{array}{l}\text { Brasil/Rio de } \\
\text { Janeiro }\end{array}$ & BDENF & 2005 \\
\hline $\begin{array}{l}\text { 48- Concepciones } \\
\text { pedagógicas en el } \\
\text { proceso } \\
\text { enseñanza- } \\
\text { aprendizaje: una } \\
\text { visión reflexiva } \\
\text { de los alumnos de } \\
\text { graduación en } \\
\text { enfermería }\end{array}$ & $\begin{array}{l}\text { Concepción de la } \\
\text { Escuela Crítica } \\
\text { (teorias pro- } \\
\text { gresistas, interacio- } \\
\text { nistas) }\end{array}$ & $\begin{array}{l}\text { Evaluación dentro de } \\
\text { la perspectiva } \\
\text { crítico-dialógica }\end{array}$ & $\begin{array}{l}\text { Revista Ciência, } \\
\text { Cuidado e Saúde }\end{array}$ & $\begin{array}{c}\text { Brasil// } \\
\text { PR-Maringá }\end{array}$ & BDENF & 2004 \\
\hline $\begin{array}{l}\text { 49- Plan de aula: } \\
\text { conceptos y } \\
\text { metodología }\end{array}$ & $\begin{array}{l}\text { Concepción de la } \\
\text { Escuela Crítica }\end{array}$ & $\begin{array}{c}\text { Evaluación } \\
\text { Diagnóstica/Sumativa } \\
\text { y Formativa }\end{array}$ & $\begin{array}{l}\text { Revista Acta } \\
\text { Paulista }\end{array}$ & Brasil/São Paulo & BDENF & 2004 \\
\hline $\begin{array}{l}50-\text { La } \\
\text { contribución de } \\
\text { Paulo Freire a la } \\
\text { práctica de } \\
\text { educación crítica } \\
\text { en enfermería }\end{array}$ & $\begin{array}{l}\text { Concepción de la } \\
\text { Escuela Crítica }\end{array}$ & No apunta & $\begin{array}{c}\text { Revista } \\
\text { Latino-Americana } \\
\text { de Enfermagem }\end{array}$ & Brasil/São Paulo & BDENF & 2004 \\
\hline
\end{tabular}

Fuente: síntesis de investigadora.

\section{UN ESCENARIO DE ANÁLISIS Y RESULTADOS}

Basándonos en los resultados de este estudio, se observa que las diferentes concepciones pedagógicas adoptadas en la evaluación del proceso de enseñanza-aprendizaje en los cursos de graduación en enfermería pueden variar en un continuo, tanto en la Escuela 
En relación a las tendencias o modelos pedagógicos de evaluación utilizados en los 50 artículos, se identificó que las concepciones de la Escuela Tradicional aparecieron en solo nueve estudios; mientras que tres estudios indicaron que la enseñanza debe pautarse en las tendencias educativas progresistas y se encuentra en transición, "migrando" para la Escuela Crítica. 41 estudios apuntaban al referencial pedagógico de la Escuela Crítica, orientada por los principios de las teorías socioconstructivistas interaccionistas, lo que demuestra estar relacionados con el reconocimiento de la importancia de un referencial pedagógico o de la consciencia del mismo en un proyecto pedagógico.

En las concepciones pedagógicas que apuntan a la transformación, las principales tendencias de evaluación del proceso enseñanza y aprendizaje proponen: una evaluación formativa, que surge como un recurso también de aprendizaje por involucrar a los alumnos en la evaluación de sus competencias, explicitando y debatiendo los objetivos y los criterios, favoreciendo la evaluación mutua, los balances de conocimientos y la autoevalaución; la evaluación como una acción provocativa del profesor, desafiando al alumno a reflexionar sobre las experiencias vividas, a formular y reformular hipótesis, direccionando para un saber enriquecido; al profesor para que aprenda la diferencia fundamental entre verificación y evaluación, donde la primera es un acto estático y la segunda un proceso dinámico que reencamina la acción-reflexión-acción; que la evaluación sea diagnóstica. Utilizada como una función diagnóstica, sería un momento dialéctico del proceso para avanzar en el desarrollo de la acción, del crecimiento para la autonomía y competencia.

En relación a las publicaciones de esas tendencias o modelos de evaluación, verificamos que los periódicos nacionales que publicaron el mayor número de artículos fueron la Revista Brasileira de Enfermagem (primer periódico de enfermería nacional y órgano oficial de divulgación de la Associação Brasileira de Enfermagem - ABEn), seguida de la Revista Latino-Americana de Enfermagem (primero periódico de enfermería nacional indexado en SciELO), de la Revista da Escola de Enfermagem da USP y de la Revista de Enfermagem da UERJ. A partir del año de 2006, constatamos un creciente aumento de publicaciones. Acreditamos que la adherencia de los cursos de graduación en enfermería a las DCNEnf fue uno de los factores determinantes para el desarrollo de la enseñanza superior de enfermería en Brasil, contribuyendo decisivamente a la construcción del conocimiento.

En cuanto a los métodos de enseñanza o estrategias pedagógicas, las DCNEnf proponen en su artículo 14, que la estructura de los cursos de graduación en enfermería deberá asegurar "la implementación de una metodología en el proceso enseñar-aprender que estimule al alumno a reflexionar sobre la realidad social y que aprenda a aprender" (3). El dispositivo legal solo indica lo que se espera de la estrategia pedagógica, particularmente en el ámbito de la práctica educativa, teniendo en cuenta los requerimientos de las políticas de inclusión social en el ámbito de la formación de enfermeros.

Una perspectiva posible para entender este proceso fue verificar que en nueve artículos que adoptaron la concepción de la Escuela Tradicional, las prácticas pedagógicas de los docentes del curso de graduación en enfermería continúan enraizadas en la concepción bancaria de la educación, que aliena, cimenta y reproduce posturas equivocadas y distorsionadas $^{(6)}$. Por ello, no todas las estrategias pedagógicas utilizadas en el proceso de formación de enfermeros, aseguran o promueven una formación profesional con las características propuestas por la referida legislación. En la práctica educativa del enfoque tradicional, por ejemplo, no hay estímulo para la reflexión y la realidad social difícilmente es tomada como substrato del proceso de enseñanza- aprendizaje. 
Se observó principalmente que el proceso evaluativo derivado de esa concepción tiende a la reproducción de los contenidos transmitidos con precisión y en cantidad, y todavía prevalece la realización de evaluaciones a través de pruebas, exámenes, llamadas orales, ejercicios de fijación. El profesor en esa Escuela tiene el papel nuclear en la conducción del aprendizaje de los alumnos. Se ignoran, de este modo, las diferencias individuales de los alumnos, evaluando a todos según los mismos criterios. Hay una fuerte tendencia a tratarse todos de forma igual, uniformizando el ritual de trabajo, en busca de la adquisición de los mismos conocimientos, de modo a alcanzar los mismos objetivos de aprendizaje. En este enfoque, el vínculo professor-alumno es vertical. En uno de los polos está el profesor, que detenta el poder de decisión en cuanto a metodología, al contenido, a la evaluación y a la forma de interacción, entre otros ${ }^{(7)}$.

Algunos estudios revelan cierto deseo, "todavía silencioso", de ver reflejado en el docente y discente, la consciencia crítica y creadora de la educación, evidenciado en una investigación realizada con graduandos de enfermería de una universidad pública. El objetivo fue saber las opiniones de los estudiantes en relación a la experiencia de participar de una dramatización insertada dentro de la disciplina de Historia de la Enfermería y la importancia de ese recurso en el proceso de enseñanza-aprendizaje ${ }^{(8)}$.

Los resultados de la investigación indican que los alumnos, al hacer la valoración de sus profesores, resaltaron su competencia técnica, 'pero también hacen referencia a la falta de didáctica, al empleo excesivo y exclusivo de la "conferencia", o sea, del aula expositiva, con bajísima participación de los alumnos. A pesar de esto, hubo una aceptación positiva por parte de los graduandos en lo que concierne al uso de la dramatización en el proceso enseñanza-aprendizaje. La utilización de estrategias de enseñanza no convencionales es atractiva y propicia la mejor asimilación del contenido programático, lo que indica que tal recurso merece ser considerado como una alternativa al proceso de enseñar y de aprender en enfermería ${ }^{(8)}$.

Esta experiencia refuerza las afirmaciones anteriormente expuestas, teniendo en cuenta que en algunos cursos de graduación en enfermería existen iniciativas de profesores mostrando su preocupación con los métodos de enseñanza utilizados en el aula. Pero generalmente son tentativas aisladas que causan poco impacto, pues los cambios tienen que ser procesados a pasos muy lentos en relación a las grandes transformaciones por las que estamos pasando.

Desde esta perspectiva, el análisis de los resultados confirmó en 41 estudios que existe un predominio del modelo de evaluación por competencias, adoptando metodologías abiertas, críticas y reflexivas, alineadas con los referenciales teóricos progresistas constructivistas y sociointeraccionistas. Este movimiento propicia que el currículo busque la integridad, originada en la combinación de atributos (cognitivos, actitudinales y habilidades) que orienta los procesos pedagógicos, priorizando la práctica profesional en distintos contextos, según los patrones socialmente construidos. En ese sentido, los textos señalaron una inclinación teórico-metodológica orientada en consonancia con las DCN, que establecen las competencias y habilidades a ser desarrolladas en el proceso de formación de los(as) enfermeros(as).

Es también en esa perspectiva, donde incluimos la evaluación bajo la orientación epistemológica que vincula individuo-sociedad, que parte del presupuesto de que el individuo se constituye al mismo tiempo sujeto y objeto del conocimiento inserto en la dinámica social históricamente construida. El desafío del cambio de la práctica evaluativa en enseñanza y aprendizaje se encuentra en el presupuesto de que el profesor se libere del uso 
autoritario de la evaluación que el sistema le faculta y autoriza, empeñándose en construir una nueva práctica, adoptando el papel de educador, cambiando el centro de su acción de fiscalizar/medir/juzgar para propiciar el compromiso con el aprendizaje de todos los alumnos.

De entre las varias interpretaciones de esas directrices por los autores de los trabajos investigados, se encuentra el estudio que tuvo como objetivo analizar los sentidos de la evaluación en la formación de enfermeros orientada por competencias, utilizando el referencial de análisis de las prácticas discursivas y la producción de sentidos en el cotidiano. Los datos fueron colectados en un grupo focal, compuesto por siete profesores del Curso de Enfermagem da Faculdade de Medicina de Marília, que tenía un currículo integrado y orientado por competencias.

Al analizarse el conjunto de la muestra, verificamos que algunos repertorios linguísticos utilizados se relacionan con la evaluación tradicional, orientada a la clasificación, sirviendo al sistema social vigente. Mas también observamos la presencia de repertorios que indican sentidos de una práctica dirigida al compromiso con el aprendizaje de todos, basada en la evaluación democrática para inclusión y transformación de la realidad social, como podemos observar en las interanimaciones dialógicas entre P7 y P6, presentadas a continuación ${ }^{\text {(9:643) }}$ :

[...] la evaluación es un "juicio" que el "profesor" hace del "estudiante", en varios "momentos", para reconocer el "avance" y las "dificultades". Explica, que al ser identificadas tales dificultades, se puede individualizar un poco el proceso", por entender que a veces, "un alumno precisa más atención que otro". También refiere que los profesores desean que "todo el mundo aprenda" y se torne un enfermero con "todas aquellas habilidades" y "características definidas en el proyecto" del Curso de Enfermería. Por ello, destaca que a pesar de esta intención para la evaluación, los profesores tienen dificultad para utilizar "esta actividad de evaluación" con el fin de atender los propósitos de la formación (P7). Sin embargo, para P6, esta limitación de los profesores se refiere a la "falta de habilidad [...] de hacer evaluación en proceso" y "trabajar en el día a día" con los estudiantes. $Y$ que las dificultades de los estudiantes han sido expresadas por los profesores, en momentos formales de evaluación (P6).

En lo que se refiere a los instrumentos utilizados en el proceso evaluativo del aprendizaje, los estudios confirmaron una diversidad de instrumentos que son empleados de forma combinada, como scripts de autoevaluación, estudio de casos, pruebas con cuestiones objetivas y subjetivas y el portafolio. Algunos cursos de graduación en enfermería utilizan como estrategia de aprendizaje y mediando ayudas para evaluación del estudiante la elaboración/organización del portafolio reflexivo, a fin de mejorar la destreza del lenguaje escrito y la capacidad de reflexión y crítica sobre determinado asunto o contenido. Para ello, se establece un límite para la fecha de entrega, de forma a disciplinar la conducta de los alumnos en el transcurso de este proceso de acción-reflexión-acción ${ }^{(10)}$.

Así, siguiendo el método propuesto para el estudio, agrupamos las seis categorías, incluyendo las escuelas pedagógicas y las tendencias o modelos de evaluación que más destacaron y utilizaron el enfoque metodológico cualitativo: las Metodologías Activas de Aprendizaje; el Modelo por Competencias; la Sociopoética; la Pedagogía Problematizadora; el Modelo de Educación de Laboratorio y el Método de Aprendizaje Basado en Problemas. 


\section{- Categoría 01 - Las Metodologías Activas de Aprendizaje}

La escuela, en esta metodología, no se encierra en su espacio físico, habiendo diversidad de posibilidades de escenarios educativos, así como de sus actores. Estos presupuestos van en contra de concepciones más tradicionales en que el alumno es considerado tabla rasa o el profesor, detentor del conocimiento, transmite este al alumno directamente en una relación vertical, siendo la escuela el único espacio pedagógico.

En las metodologías activas el alumno/educando es entendido como una persona que tiene un bagaje cognitivo-afectivo importante, además de una cultura subyacente que lo identifica con una realidad contextualizada, y esto es un importante aspecto cuando se trata de un país continental como Brasil. El papel del profesor/educador es el de indicarr caminos que el alumno pueda seguir para su formación, actuando desde la postura de facilitador, problematizando las situaciones vividas en el cotidiano y los espacios de formación. O sea, el estudiante se coloca al lado del profesor, que tiene la tarea de orientar y dirigir el proceso educativo como un ser que también busca el conocimiento. Dialogar con el estudiante no significa delegar en él toda la elaboración del problema, mas lo lleva a un análisis profundo de la problemática, a fin de que pueda descubrir la totalidad y predisponerse a desnudarla para responder a las cuestiones propuestas ${ }^{(11)}$.

Una práctica evaluativa coherente con esta perspectiva sugiere el uso del portafolio, o pasta evaluativa, como un instrumento eficaz, en consonancia con la naturaleza evolutiva del proceso de aprendizaje. El portafolio evidencia al mismo tiempo, tanto para el educando como para el educador, procesos de autorreflexión y permite al profesor repensar su práctica y sus conductas pedagógicas en vez de solamente hacer algun juicio de valor, evaluar o clasificar el proceso de aprendizaje del alumno. Se presenta como una posibilidad interesante para evaluar el aprendizaje del alumno, de modo continuo y procesal (notas escolares de los alumnos y testimonios recogidos por medio de hojas de registro), siendo instrumento de diálogo entre educador y educando que no es producido solamente en el término del periodo para fines evaluativos, sino también comprendido como un instrumento de estimulación del pensamiento reflexivo, facilitando oportunidades para documentar, registrar y estructurar los procedimientos y el propio aprendizaje ${ }^{(11)}$.

Igualmente, es importante destacar que en ese proceso de continua reflexión, los alumnos por sí mismos explican cómo construyen su aprendizaje, cómo dialogan con los problemas al reevaluar en qué medidas superaron las dificultades, o si tras valorizarlas, continúan aprendiendo para seguir adelante. Se sugiere la realización de estudios más sistematizados, buscando ampliar el repertorio de conocimientos sobre este sistema de evaluación $n^{(11)}$.

\section{- Categoría 02 - Modelo por Competencias}

El modelo por competencias valora la postura activa del aprendiz en el proceso, por considerarlo tan actor del aprendizaje como el que enseña. Están determinadas las reglas del grupo y los criterios de evaluación dentro de una perspectiva de gestión compartida de la disciplina, en la cual la participación del grupo es indispensable. La evaluación es guiada en cinco dimensiones: autoevaluación, reflexión, pensamiento crítico, administración de informaciones y habilidades en grupo.

Al comprender que el desempeño del estudiante representa la movilización de sus competencias relativas al conocimiento, las habilidades y las actitudes, la evaluación por competencias mira al crecimiento del alumno, tomando como referencia las competencias profesionales a ser adquiridas, no quedando restringido al resultado del desempeño, por 
ello, a partir de este, proyecta estrategias que favorecerán el desarrollo de las competencias necesarias al desempeño del trabajo ${ }^{(12)}$.

En la concepción constructivista por competencia, una evaluación formativa es continua y tiene como finalidad fundamental la formación integral de la persona, observando las diferentes fases experimentadas en la construcción de las habilidades deseadas por alumnos y profesores. El ejercicio de la competencia está unido a los valores humanos, principios e ideales éticos que reflejan el compromiso de la profesión con acciones dotadas de tolerancia y respeto de todos los géneros. Esa modalidad de evaluación es considerada una de las formas que han demostrado efectos positivos y cumple requisitos de la evaluación formativa en el proceso de enseñanza-aprendizaje.

En esa dimensión evaluativa son consideradas las siguientes fases: la evaluación inicial, que permite conocer cuál es la situación de partida, en función de objetivos generales bien definidos, así como conocer lo que cada alumno sabe y lo que quiere saber, cuáles son los instrumentos de que ya dispone y cuáles las limitaciones ya vivenciadas; la evaluación reguladora, que parte de los objetivos y contenidos de aprendizaje previstos, donde el profesor establece las actividades y las tareas y percibe la manera como cada alumno aprende y las necesidades de aprendizaje o alteraciones que pueden ser realizadas; la evaluación final, donde se analiza el desempeño del alumno, o sea, si alcanzó los resultados, si adquirió las competencias deseadas - el progreso de cada alumno siempre será analizado en relación a los objetivos propuestos; y la evaluación integradora, en que profesor y alumno deben discutir respecto de lo que fue desarrollado y realizar previsiones sobre lo que es necesario continuar haciendo o rehacer. Esta etapa es importante para que el alumno pueda continuar su formación, considerando sus características específicas ${ }^{(12)}$.

\section{- Categoría 03 - La Sociopoética}

En este modelo, el estudiante de enfermería es considerado "el futuro cuidador" y el primer cliente del profesor enfermero. La profundización de esta concepción teórica establece un puente para una ecología política y del espíritu, consolidando la solidaridad entre los seres humanos, así como la pluralidad de autogestión.

Cabe a los educadores de enfermería comprender la persona, el alumno, en esa plenitud para cuidar de ella en su singularidad y particularidades. Se parte, por tanto, de las concepciones de Freire, proponiendo la dialogicidad entre cuidador y cliente en una auténtica revelación, integración, interacción de saberes provenientes de sus experiencias y referenciales históricos, culturales y estructurales.

La evaluación del proceso educativo en esta metodología generalmente se realiza en grupo, debe tener el sentido de resignificación en la diversidad - el saber del sentido común comulgando con la ciencia, con el arte, inventando lo nuevo basado en la autonomía, en la creación; los clientes (alumnos o no) aprenden lo que más les interesa y lo que deben evitar para sobrevivir en el mundo de hoy ${ }^{(13)}$.

\section{- Categoría 04 - Pedagogía Problematizadora}

Esta tendencia es innovadora por sus desafíos; caracterizada por integración, totalidad, interdisciplinaridad y nueva concepción de teoría/práctica, siendo esa filosofía una importante contribución para que la educación sea entendida como una acción política y potencialmente transformadora de la realidad social. La educación acontece todo el tiempo en la relación de los sujetos unos con otros, con el mundo y consigo mismos, es un proceso 
histórico, social, cultural y permanente; está basada en el proceso dialógico-reflexivo, en la sensibilización y en el desarrollo de dinámicas colectivas.

Por ser una pedagogía problematizadora y libertadora, destaca la necesidad de los docentes y discentes de los cursos de graduación en enfermería de reflexionar profundamente acerca de esa formación, dirigiendo su mirada a la construcción de un proceso de enseñanza y aprendizaje que los valore como sujetos de la producción del saber. Esta reflexión no se acaba aquí. La evaluación en una perspectiva crítica dialógica es solo el comienzo del camino que es necesario recorrer para ser más ${ }^{(14)}$.

\section{- Categoría 05 - Modelo de Educación de Laboratorio}

Educación de laboratorio es un término genérico, aplicado a un conjunto de metodologías que atienden cambios personales a partir de aprendizajes basados en experiencias directas o vivencias. Es un referencial constructivista, que preconiza que varios referenciales teóricos (behaviorista, cognitivo o humanístico) del proceso enseñanza-aprendizaje pueden ser accionados en este modelo, desde que se consideran pertinentes las tareas, actitudes 0 comportamientos que se esperan del aprendiz.

Esa corriente permite también discutir las posibilidades de cambios en el modo de pensar y actuar de los alumnos, por medio de la validación de la teoría construida y de las observaciones de la vivencia y análisis del proceso del grupo. Se espera que esto sea potencializado por la dinámica de trabajo grupal, que permite la articulación entre base teórica, reflexión y experiencia concreta, viabilizando un aprendizaje significativo, permanente, propicio para el desarrollo de tecnologías leves, tan necesarias en el contexto del trabajo en salud ${ }^{(15)}$.

En este modelo, la evaluación del aprendizaje es por competencias, valorándose la postura activa del aprendiz en el proceso, por considerarlo tan actor de lo aprendido como el que enseña. Están determinadas las reglas del grupo y los criterios de evaluación dentro de una perspectiva de gestión compartida de la disciplina, en la que la participación del grupo es indispensable.

\section{- Categoría 06 - Método de Aprendizaje Basado en Problemas}

Este método es un modelo de tutoría fundamentado en las teorías constructivistas de aprendizaje, en los principios de aprendizaje de los adultos y en el desarrollo de modelos andragógicos, cuyo propósito es ayudar a los alumnos a desarrollar habilidades para dirigir su propio aprendizaje. Se trata de una nueva forma de aprender que determina nuevas maneras de enseñar.

Es un método procesal en el que los individuos con iniciativas propias, con o sin ayuda de los profesores, hacen el diagnóstico de sus necesidades de aprendizaje, formulan sus metas de aprendizaje, identifican los recursos humanos y necesarios para aprender, eligen y aplican estrategias de aprendizaje adecuadas y evalúan los resultados del aprendizaje.

El proceso evaluativo es por competencias, y en él son consideradas cinco habilidades: autoevaluación, reflexión, pensamiento crítico, administración de informaciones y habilidades de grupo. El profesor en esa metodología es un tutor-facilitador del proceso de enseñanza aprendizaje de los alumnos. Para que ello suceda, el curso de enfermería disponibiliza todas las estrategias, mecanismos e instrumentos posibles para que los profesores desarrollen estas habilidades con los alumnos ${ }^{(16)}$. 
Con relación a esas tendencias o modelos de evaluación, se observó que son construidos a partir de la reforma curricular y de los proyectos políticos pedagógicos (PPPs) de curso, de forma integrada (teoría/práctica). Se pauta en las DCN y en los cuatros pilares de la educación, los cuales preconizan que la formación profesional no se restrinja solamente a la competencia técnica, sino que contemple también las competencias políticas, éticas y humanas.

Por otro lado, los cambios en las tendencias o modelos cualitativos suceden a partir de relatorios para fines de reconocimiento y renovación de reconocimiento de cursos; de situaciones-problema, ajustadas al nivel de los alumnos, al alcance individual de cada uno, lo que implica la necesidad de saber conducir racionalmente esta heterogeneidad; de la inserción de nuevas herramientas y/o instrumentos facilitadores en la enseñanza de enfermería, como la utilización de la música y de las artes en general, que con sus elementos formales sirven de apoyo en la práctica pedagógica y, consecuentemente, pueden contribuir a la aparición de un proceso de enseñanza-aprendizaje agradable, creativo, motivador y transformador, permitiendo que docentes y discentes se conviertan en personas más críticas y dadas al diálogo, favoreciendo para ambos un crecimiento educativo y emancipatorio.

En este sentido, la construcción de un proceso formativo basado en los cuatros pilares de la educación implica posicionamientos filosóficos y políticos y la busca de otras referencias de enseñanza y aprendizaje. Posibilita, además, que el alumno construya su camino con sensibilidad, percibiendo nuevos valores que lo ayuden a adquirir mayor autonomía y competencia, mediante un nuevo mirar, un nuevo sentir, un nuevo pensar y una nueva forma de hacer que incorpora deseos, aspiraciones, sentimientos, conflictos y comportamientos. Una estrategia para rescatar la sensibilidad en el aprender-enseñar Enfermería consiste en incorporar la alegría como elemento que estimula la imaginación y permite la construcción de significados e interpretaciones que impulsan el proceso crítico-creativo ${ }^{(17)}$.

Otro aspecto relevante de la investigación fue constatar que Brasil es el escenario geográfico de América Latina que más destacó en la aplicación de la tendencia o modelo de evalaución del aprendizaje por competencias. Estas ocurrencias están distribuidas: en la Región Sudeste, Ribeirão Preto-SP; São Paulo-SP, Uberaba-MG, Rio de Janeiro-RJ; en la Región Sur, Florianópolis-SC, Cascavel-PR, Ponta Grossa-PR, Porto Alegre-RS, São Leopoldo-RS, Vale do Rio dos Sinos-RS; en la Región Nordeste, Bahia, Fortaleza-CE; en la Región Centro-Oeste, Brasília-DF. Con todo, todavía de manera incipiente, estas tendencias de evaluación son aplicadas en los cursos de graduación en enfermería de países LatinoAmericanos como el de la Universidad de Colima y el de la Universidad Autónoma de San Luis Potosí, ambas situadas en México, así como en la Facultad de Enfermería de la Universidad de Antioquia, en Medellín, Colombia.

Considerando la aplicación de esas tendencias o modelos de evaluación, destacamos que son experiencias consolidadas en diversas disciplinas teórico-prácticas vivenciadas por los Cursos de Graduación en Enfermería, en universidades públicas y privadas nacionales e internacionales, bajo la perspectiva epistemológica que vincula individuo y sociedad partiendo del presupuesto de que el individuo se constituye al mismo tiempo sujeto y objeto del conocimiento, inserto en la dinámica social históricamente construida.

Los alumnos son los protagonistas del aprendizaje, buscando construir su propio conocimiento - aprendizaje significativo -, y los profesores los mediadores de ese proceso, apoyando, ayudando, desafiando e incentivando la construcción del saber. Con todo, vale 
resaltar que en los países latinoamericanos ese cambio no es uniforme, inclusive en Brasil, ya que esa transformación sucede gradualmente, en todos los niveles y modalidades educativos.

En fin, comprender cómo están configuradas las tendencias o modelos de evaluación en la enseñanza de graduación en enfermería presupone, por un lado, que los educadores entiendan cuál es el enfoque crítico de la edución y de su acción política y social; de otro, que los educandos se transformen de agentes pasivos en la recepción de los conocimientos repassados por el profesor en seres activos, responsables de su desarrollo. Al final, lo que pasa en la mayoría de los cursos de graduación es que comúnmente el docente acaba reproduciendo los modelos de enseñanza a los que estuvo sometido en cuanto alumno, modelos muchas veces convencionales, verticalizados, que utilizan la evaluación como instrumento de clasificación del alumno y no como control de los niveles de enseñanza y aprendizaje.

En la perspectiva de la Escuela Crítica, el enfoque del modelo por competencias fue el que más destacó, y representa un paso adelante para la superación de los enfoques tradicionales, por su compatibilidad con los deseos y necesidades de renovación de la escuela; por individualizar y diversificar las rutas de formación, tanto del docente como del discente; por enfocarse a una evaluación formativa y no normativa; por desarrollar el trabajo en equipo; por colocar a los discentes en el centro de la acción pedagógica; por recorrer las metodologías activas de enseñanza-aprendizaje; por desarrollar la competencia y la transferencia de conocimientos trabajando a partir de situaciones-problema, pues la noción de competencia está anclada en matrices distintas, pudiendo ser conductora en el proceso de aprendizaje. Al final, asumir que la enseñanza por competencias es solo la punta más visible de un cambio radical de conceptos significa aceptar romper con los antiguos paradigmas, condición existencial para este enfoque ${ }^{(18)}$.

\section{ALGUNAS CONSIDERACIONES FINALES}

Al iniciar este estudio de revisión acerca de los modelos/tendencias de evaluación en la enseñanza de graduación en enfermería, evidenciando y discutiendo cómo se configuran las diferentes inclinaciones pedagógicas adoptadas en América Latina, no tuvimos la intención de agotarlo. Sabíamos, por el contrario, que se trataba de un tema no sólo complejo, sino desafiante, precisamente por la actualidad, por las divergencias conceptuales que suscita y por las posiciones contrarias derivadas de esas divergencias conceptuales, por ello inherentes a la acción educativa, en la medida en que se amplía la contradicción entre el discurso y la práctica de los docentes/educadores.

A partir de los datos encontrados, se constató que en Brasil y en países latino-americanos, algunos cursos de graduación en enfermería están pasando por reformulaciones en su estructura curricular, todavía de forma incipiente. $Y$ es preciso valorar este dato, pues existen muchos avances en las diferentes inclinacions metodológicas adoptadas en los cursos.

Las consideraciones hechas por los autores son de orden teórico. Pocos son los estudiosos que realizan investigaciones con docentes y discentes a fin de presentar datos más objetivos y consistentes para ser discutidos. La forma de evaluación como viene siendo procesada provoca algunas preocupaciones y reflexiones en varios estudiosos del área, pues las DCN señalan en su texto que debe existir el predominio de la evaluación cualitativa sobre la cuantitativa, la evaluación por critérios y por dominio, pero la definición de esos criterios no siempre anuncia la razón de su elección. 
Entre las limitaciones del estudio, destaca lo incompleto de los resúmenes analizados, la escasez de investigaciones sistemáticas sobre la evaluación del proceso enseñanzaaprendizaje en el área de Enfermería, la imprecisión de datos - lo que justifica las divergencias identificadas y la falta de claridad en los descriptores citados en los textos, dificultando la busca sobre todo de los métodos y resultados, haciéndose necesario recurrir a la busca de los textos en su totalidad en la mayoria de los periódicos.

Otra debilidad es la que se refiere al domiínio limitado de los docentes acerca de los referenciales teórico-metodológicos adoptados por los cursos de enfermería. Es esencial recordar que la metodología es fundamental, pero no debe ser más importante que el contenido. Por tanto, se debe invertir en la formación del profesor, en su capacitación técnica y didáctica para que este pueda evaluar el aprendizaje de forma clara y consistente, ofreciendo espacio para la manifestación de las dudas y los intereses del alumno.

Se recomienda nuevas investigaciones sobre la temática, estudios que exploren "nuestros" críticos de esas tendencias o modelos pedagógicos de enseñanza, pues entendemos que en el ámbito de la formación de enfermeros uno de los grandes desafíos para la renovación de los enfoques pedagógicos, que sustentan las prácticas educativas es el de compatibilizar los aspectos técnicos, políticos, socioculturales, éticos y estéticos en los procesos de formación profesional, y dirigirlos a través de un enfoque pedagógico que alimente las prácticas educativas más allá de las necesidades técnicas y las mantenga ajustadas a los movimientos de inclusión social. Esta nueva realidad requiere preparación y apertura a nuevos paradigmas, y que la evaluación se inserte en este contexto.

\section{REFERENCIAS}

1. Luck G. Avaliação - termômetro da educação. Revista Profissão Mestre. 2002; 2(12):1417.

2. Ito EE, Peres AM, Takahashi RT, Leite MMJ. O ensino de enfermagem e as diretrizes curriculares nacionais: utopia x realidade. Rev Escola Enfermagem USP. 2006; 40(4):570575.

3. Ministério da Educação (BR). Resolução CNE/CES n‥ 3, de 07 de novembro de 2001. Institui as Diretrizes Curriculares Nacionais do Curso de Graduação em Enfermagem. Brasília (DF): Diário Oficial da União; 2001.

4. Lopes Neto D, Teixeira E, Vale EG, Cunha FS, Xavier IM, Fernandes JD et al. Aderência dos cursos de graduação em enfermagem às Diretrizes Curriculares Nacionais. Rev Bras Enferm. 2007; 60(6):627-34.

5. Demo P, Hoffmann J, La Taille Y. Grandes pensadores em educação: o desafio da aprendizagem, da formação moral e da avaliação. 3. ed. Porto Alegre: Mediação; 2001.

6. Ganong LH. Integrative Review of Nursing Research. Res Nursing Health. 1987; 10(1):111.

7. Bordenave JD, Pereira AM. Estratégias de ensino-aprendizagem. 25. ed. Petrópolis (RJ): Vozes; 2004.

8. Silva RPG, Rodrigues RM. Mudança curricular: desafio de um curso de graduação em enfermagem. Rev Bras Enferm. 2008; 61(2): 233-8.

9. Barros MA, Cyrillo CCP. A dramatização como recurso no processo ensino-aprendizagem 
na disciplina de história da enfermagem. Cogitare Enferm. 2006; 11(1): 44-49.

10. Laluna MCMC, Ferraz CA. Finalidades e função da avaliação na formação de enfermeiros. Rev Bras Enferm.2007; 60(6): 641-5.

11. Tanji S, Silva CMSLMD. As potencialidades e fragilidades do portfólio reflexivo na visão dos estudantes de enfermagem. Rev. Enferm UERJ. 2008; 16(3): 392-8.

12. Reibnitz KS, Prado ML. Processo de trabalho, processo educativo e formação em enfermagem. In: Reibnitz KS, Prado ML, organizadores. Inovação e Educação em Enfermagem. Florianópolis: Cidade Futura; 2006. p. 79-108.

13. Perrenoud P. Avaliação: da excelência à regulação das aprendizagens. Porto Alegre: Artes Médicas Sul; 1999.

14. Santos I. Rev. Enferm UERJ. 2007; 15(1):113-8.

15. Freire P. Pedagogia do oprimido. 29. ed. Rio de Janeiro: Paz e Terra; 2005.

16. Munari DB, Oliveira NF, Fernandes CNS. O modelo de educação de laboratório na formação do enfermeiro: avaliação do graduando de enfermagem. Rev. Enferm UERJ. 2006; 14(3): 385-90.

17. Prado ML, Reibnitz KS, Gelbcke FL. Aprendendo a cuidar: a sensibilidade como elemento plasmático para formação da profissional crítico-criativa em enfermagem. Texto \& Contexto Enferm. 2006; 15(2):296-302.

18. Hoffmann J. Avaliação - mito e desafio: uma perspectiva construtivista. 39. ed. Porto Alegre: Mediação; 2008. 